\title{
Tungstated zirconia catalyzed bromination of phenol red under nearly neutral solution
}

\author{
She-Tin Wong ${ }^{\text {a }}$, Chi-Chau Hwang ${ }^{\text {a }}$, Chung-Yuan Mou ${ }^{\text {a,b,* }}$ \\ ${ }^{a}$ Department of Chemistry, National Taiwan University, Taipei 106, Taiwan, ROC \\ ${ }^{\mathrm{b}}$ Center of Condensed Matter Science, National Taiwan University, Taipei 106, Taiwan, ROC
}

Received 12 May 2005; received in revised form 20 July 2005; accepted 8 August 2005

Available online 13 October 2005

\begin{abstract}
The performance of tungstated zirconia catalysts prepared by co-precipitation (WZ) and impregnation $\left(\mathrm{W} / \mathrm{m}-\mathrm{ZrO}{ }_{2}\right)$ techniques in phenol red bromination reaction was tested. Both types of catalysts showed excellent activity in this reaction in aqueous solution. The activity of WZ increases as the $\mathrm{W}$ loading decreases and the most active $0.6 \mathrm{WZ}$ catalyst contained highly dispersed $\mathrm{WO}_{x}$ of low surface density on zirconia. The $\mathrm{W} / \mathrm{m}-\mathrm{ZrO} \mathrm{O}_{2}$ catalysts showed even higher activity in this reaction but maximum performance is observed for $1.3 \mathrm{~W} / \mathrm{m}-\mathrm{ZrO}_{2}$ instead. The active site for the redox reaction is probably the monomer or dimer of $\mathrm{WO}_{x}$ with a single oxo group whereas low surface density of $\mathrm{WO}_{x}$ provides enough space on zirconia for the adsorption of phenol red without blocking the redox sites.
\end{abstract}

(C) 2005 Elsevier B.V. All rights reserved.

Keywords: Tungstated zirconia; Mesoporous zirconia; Phenol red; Bromination; XPS; EXAFS

\section{Introduction}

Bromination of aromatic compounds is a class of reactions of both laboratory and industrial importance. Often, bromination of aromatic substrates is performed with elemental bromine which is difficult to handle. The substitution reaction, with the formation of hydrobromic acid as a by-product, would reduce the atom efficiency by $50 \%$. Also the generated hydrobromic acid must be neutralized before it can be discharged. In order to overcome these problems, an environmentally friendly process may involve oxidation of a bromide anion using a suitable oxidant such as hydrogen peroxide under nearly neutral solution. This concept has been inspired by the enzymes, vanadium dependent bromoperoxidases (VBPO). VBPO can be found in most marine organisms and has been used for the synthesis of halogenated compounds which may play the role of chemical defense [1]. It catalyzes the oxidation of a halide (i.e. $\mathrm{Cl}^{-}, \mathrm{Br}^{-}$, or $\mathrm{I}^{-}$) by hydrogen peroxide which is then used for the subsequent halogenation reactions. Many of these halogenated compounds have been used widely in pharmaceutical research due to their biological activities. However, the direct use of haloperoxidase in large-

\footnotetext{
* Corresponding author. Fax: +886223660954.

E-mail address: cymou@ntu.edu.tw (C.-Y. Mou).
}

scale synthesis may not be practical since high cost is involved in the cultivation, extraction and purification of this enzyme from its source. An alternative approach is to find a biomimetic halogenation catalyst instead.

Bromination of phenol red is often used as the test reaction for these biomimetic catalysts since it is facile and can be followed easily by UV-visible absorption technique. A proposed reaction pathway through the formation of " $\mathrm{OBr}^{-}$", " intermediate is outlined in scheme (1) [1]:

$\mathrm{Br}^{-}+\mathrm{H}_{2} \mathrm{O}_{2} \rightarrow$ ' $\mathrm{OBr}^{-}, "+\mathrm{H}_{2} \mathrm{O}$

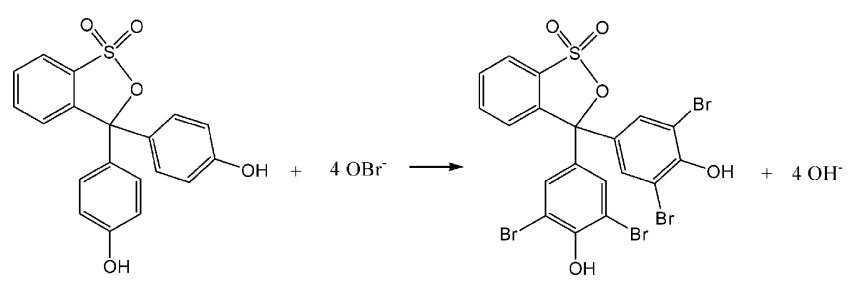

It has been suggested that there exist an equilibrium mixture of bromine intermediates in aqueous solution such as $\mathrm{HOBr}, \mathrm{Br}_{3}{ }^{+}$, $\mathrm{Br}_{2}$, and even $\mathrm{Br}$ species coordinated to the catalyst. 
Oxo-peroxo species of early transition metals have been employed as biomimetic catalyst for such reaction. A recent example is a penta-coordinated oxo-peroxo vanadium (V) complex catalyzing the bromination of phenol red [2]. However, for homogeneous catalyst, high concentrations of metal relative to reactants are often needed. The separation cost is a further disadvantage.

Recently, Sels et al. [3-6] have prepared a series of tungstate ion $\left(\mathrm{WO}_{4}{ }^{2-}\right.$ ) exchanged layered double hydroxides (LDH) and they showed the highest activity so far in phenol red bromination reaction at nearly neutral $\mathrm{pH}$ condition. Previous studies involving homogeneous catalysts in solution required strong acidic condition for promising results. However, tungstate ion may leach from LDH over long term. It is also known that the LDH structure would dehydroxylate or form new compound with various surface anions at high temperature. In addition, being basic in nature, $\mathrm{LDH}$ is not very stable in acidic medium [7]. Stucky and co-workers on the other hand have functionalized mesoporous silica MCM-48 with tungsten and molybdenum [8]. The resulting surface metal-oxo species showed catalytic peroxide activation. However, their bromination activities are apparently rather low and no details on catalysis are given. It seems that silica is a poor support for tungstate to generate the necessary surface acidic and redox species for the catalysis.

Tungstated zirconia, $\mathrm{WO}_{x} / \mathrm{ZrO}_{2}$, is a versatile catalyst in that it can catalyze both acid and redox type of reactions. So far, this class of catalyst is only well-known for the study of acidcatalyzed reaction such as the isomerization of $o$-xylene and $n$-alkane $[9,10]$. However, Lewis acid can also promote oxidation reaction by coordinating with a peroxy species and enhancing dramatically the electrophilicity of these oxidizing reagents toward their reaction with weakly nucleophilic substrates such as bromide. Tungstated zirconia is known to have Lewis acid sites on their surfaces [10].

Normally, loadings higher than full monolayer coverage of $\mathrm{WO}_{x}$ on zirconia are required for maximum acidic catalytic performance such as in isomerization [10]. For biomimetic bromoperoxidation reaction, the active center seems to be monomeric or dimeric species. Now, highly dispersed $\mathrm{WO}_{x}$ surface sites are required for the efficient oxidation of $\mathrm{Br}^{-}$ before electrophilic substitution into the hydrocarbon structure occurs. In this paper, we shall report the catalytic properties of tungstated zirconia in the bromination of phenol red. We report the preparation (co-precipitation and impregnation), characterization (XPS, EXAFS, EPR, IR), and catalytic bromination reaction of phenol red over tungstated zirconia catalysts. Very high turn-over frequency is obtained for catalysts with highly dispersed $\mathrm{WO}_{x}$ on the surface.

\section{Experimental}

In our study, two kinds of tungstated zirconia catalysts were used: the catalysts prepared by co-precipitation technique were denoted as WZ, whereas those prepared by impregnation technique were denoted as $\mathrm{W} / \mathrm{m}-\mathrm{ZrO}_{2}$. It should be noted that mesoporous zirconia $\left(\mathrm{m}-\mathrm{ZrO}_{2}\right)$ was used for the latter method.
The preparation procedure for $\mathrm{WZ}$ and $\mathrm{W} / \mathrm{m}-\mathrm{ZrO}_{2}$ are outlined below.

WZ catalyst was prepared by the method previously reported by us [10]. Briefly, the hydroxide precursor of WZ was obtained by co-precipitation technique from a solution of zirconyl nitrate hydrate, $\mathrm{ZrO}\left(\mathrm{NO}_{3}\right)_{2} \cdot x \mathrm{H}_{2} \mathrm{O}$, by adding dropwise a solution containing $\mathrm{NH}_{4} \mathrm{OH}$ and ammonium metatungstate hydrate $\left(\mathrm{NH}_{4}\right)_{6} \mathrm{~W}_{12} \mathrm{O}_{39} \cdot x \mathrm{H}_{2} \mathrm{O}$. After hydrothermal reaction and separation, the precursor was calcined in static air for $3 \mathrm{~h}$ at 600 or $800{ }^{\circ} \mathrm{C}$ (for $13.7 \mathrm{WZ}$ ). The resulting catalyst is denoted as $x \mathrm{WZ}$, where $x$ is the weight percent of tungsten in $\mathrm{WZ}$.

Hexadecyl trimethyl ammonium bromide $\left(\mathrm{C}_{16} \mathrm{TAB}\right)$ was used as the template for the synthesis of mesoporous zirconium oxide (designated as $\mathrm{m}-\mathrm{ZrO}_{2}$ ). Mesoporous zirconia was prepared according to the method outlined in reference [11], and has been well characterized [12]. $x \mathrm{~W} / \mathrm{m}-\mathrm{ZrO}_{2}(x$ denotes weight percent of $\mathrm{W}$ ) was prepared by impregnating $\left(\mathrm{NH}_{4}\right)_{6} \mathrm{~W}_{12} \mathrm{O}_{39} \cdot x \mathrm{H}_{2} \mathrm{O}$ on mesoporous zirconia and calcined at $630{ }^{\circ} \mathrm{C}$ for $4 \mathrm{~h}$.

Elemental composition was analyzed with a simultaneous ICP-AES allied analytical system (Jarrel-Ash, Model ICAP 9000). X-ray diffraction (XRD) analysis was done with powdered samples on Philips Expert instrument. Nitrogen adsorption-desorption data were obtained at $-196{ }^{\circ} \mathrm{C}$ on a Micromeritics ASAP 2000 apparatus and were analyzed for BET surface area and pore size distribution. Ultraviolet-visible (UV-vis) absorption spectra were taken on a Hitachi U-3010 spectrophotometer. Infrared (IR) spectra were recorded on a Nicolet Magna-IR 550 spectrometer. A Bruker EMX EPR spectrometer (X-band) was employed to measure the electron paramagnetic resonance (EPR) spectra of the sample.

The study on X-ray photoelectron spectroscopy (XPS) was carried out on a VG Scientific ESCALAB 250 XPS instrument with an incident X-ray energy of $1486.8 \mathrm{eV}(\mathrm{Al} \mathrm{K} \alpha)$. The binding energy $(\mathrm{BE})$ of $\mathrm{C} 1 \mathrm{~s}$ peak $(284.8 \mathrm{eV})$ in the spectrum is used as the internal reference for energy calibration. Data analysis involved smoothing, non-linear Shirley-type background subtraction and curve-fitting using mixed GaussianLorentzian functions.

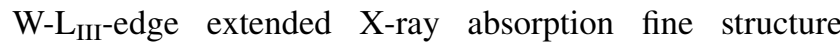
(EXAFS) study was performed at the National Synchrotron Radiation Research Center in Hsinchu, Taiwan. The electron storage ring was operated at about $1.5 \mathrm{GeV}$ with a ring current of about $200 \mathrm{~mA}$. All the experiments were done at room temperature. The resulting EXAFS data were analyzed with standard FEFF6 program. Special scanning procedure was employed for the highly dispersed $0.6 \mathrm{WZ}$ catalyst. It was done in the fluorescence mode and each scan took twice as long as the other catalysts. Six such scans were average to give a better spectrum.

Bromination of phenol red to bromophenol blue was carried out at room temperature and monitored using UV-vis spectroscopy. The solvent used was either water or a mixture of water, methanol and tetrahydrofuran where the volume ratio of $\mathrm{H}_{2} \mathrm{O}: \mathrm{CH}_{3} \mathrm{OH}: \mathrm{C}_{4} \mathrm{H}_{8} \mathrm{O}$ is 4:3:2 [4]. The solid catalyst was removed before each measurement. The reaction conditions for the catalysis are listed in the table of catalytic results. 


\section{Results}

\subsection{XRD study}

Fig. 1 compares the XRD patterns of WZ with different $\mathrm{W}$ loadings. No diffraction peaks due to $\mathrm{WO}_{x}$ crystallites at $2 \theta=23.2,23.6$ and $24.4^{\circ}$ are observed on samples with $\mathrm{W}$ loading $<13.7 \mathrm{wt} \%$. It should be pointed out that the peak at $\sim 24.3^{\circ}$ for samples with $\mathrm{W}$ loading $<13.7 \mathrm{wt} \%$ is due to monoclinic zirconia and not $\mathrm{WO}_{x}$ crystallites [13]. Tetragonal zirconia is only observed in $13.7 \mathrm{WZ}$ but monoclinic zirconia becomes increasingly prominent as the $\mathrm{W}$ loading decreases.

\subsection{IR study}

The IR spectrum of $0.6 \mathrm{WZ}$ is shown in Fig. 2. Before dehydration, adsorbed water led to a broad band at 2800$3700 \mathrm{~cm}^{-1}$ and a sharp band at $1628 \mathrm{~cm}^{-1}$, both of which are much diminished after drying. Pure tetragonal $\mathrm{ZrO}_{2}$ would show surface hydroxyl bands between 3600 and $3800 \mathrm{~cm}^{-1}$ $[14,15]$. In our $0.6 \mathrm{WZ}$ sample, we only see a very weak bump centered at $3448 \mathrm{~cm}^{-1}$ confirming surface anchoring of W. We also demonstrate that $0.6 \mathrm{WZ}$ adsorbs not only water but also carbon dioxide. When the spectrum was taken immediately after drying at $100{ }^{\circ} \mathrm{C}$, absorption bands around $2353 \mathrm{~cm}^{-1}$ due to adsorbed $\mathrm{CO}_{2}$ appeared. It is known that zirconia possesses surface basic sites in addition to acidic sites [14,15]. Apparently, $\mathrm{CO}_{2}$ was preferentially adsorbed on some basic sites of partially exposed zirconia surface in $0.6 \mathrm{WZ}$. When the $0.6 \mathrm{WZ}$ sample was allowed to stand for $1 \mathrm{~h}$ in static air, the $\mathrm{CO}_{2}$ absorption bands disappeared again. We also noted that the amount of adsorbed $\mathrm{CO}_{2}$ decreases as the $\mathrm{W}$ loading increases.

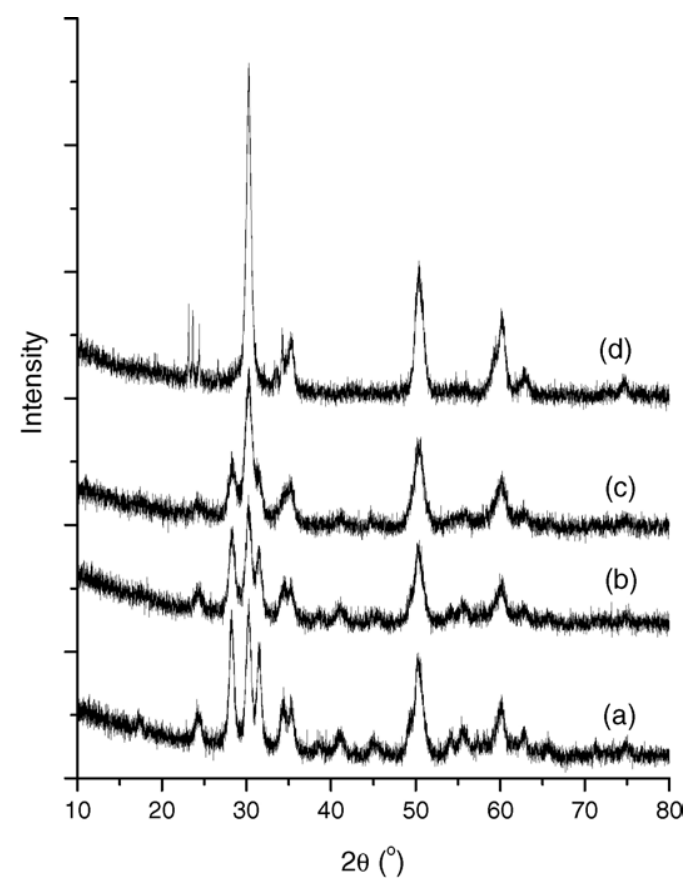

Fig. 1. XRD patterns of (a) 0.6WZ; (b) 3.3WZ; (c) 10.1WZ; (d) $13.7 \mathrm{WZ}$.

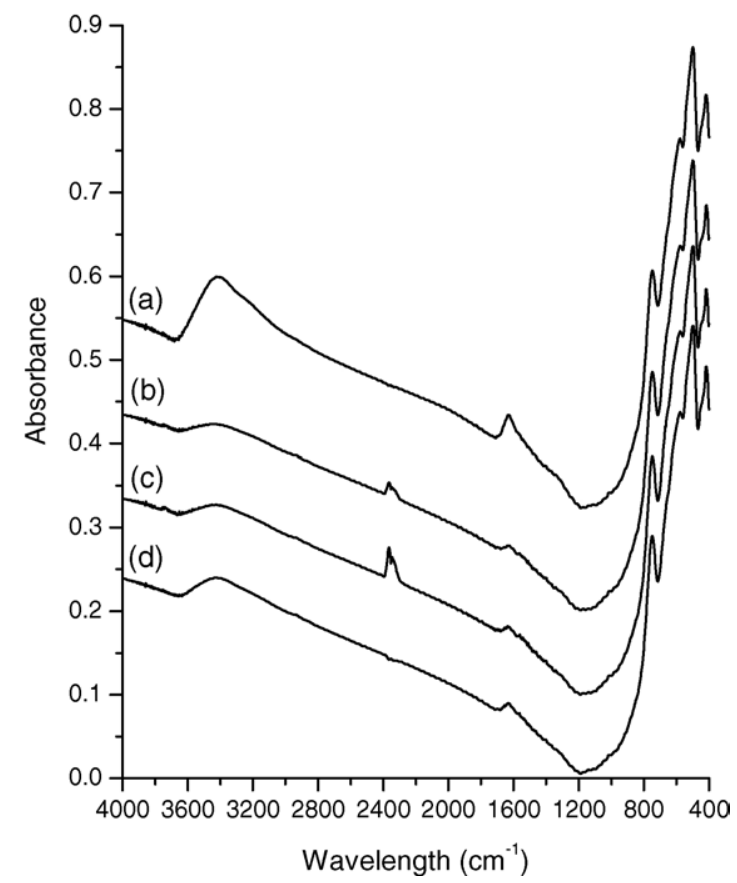

Fig. 2. IR spectra of $0.6 \mathrm{WZ}$ (a) as-synthesized; (b) after $100{ }^{\circ} \mathrm{C}$ drying; (c) repeated scan; (d) after $1 \mathrm{~h}$ standing.

This is understandable since the zirconia surface sites would diminish as the $\mathrm{WO}_{x}$ coverage is increased.

\subsection{XPS study}

We have also measured the $\mathrm{W} 4 \mathrm{f}$ and $\mathrm{Zr} 3 \mathrm{~d}$ XPS spectra of $\mathrm{WZ}$ at different $\mathrm{W}$ loadings (Fig. 3). W $4 \mathrm{f}$ peaks becomes prominent only in the high W-loading sample (13.7WZ). The $\mathrm{Zr} 3 \mathrm{~d}$ (and $4 \mathrm{p}$ ) peaks shifted to higher BE as the $\mathrm{W}$ loading increases and this indicates the flow of electron density from zirconia phase into $\mathrm{WO}_{x}$ phase through the $\mathrm{Zr}-\mathrm{O}-\mathrm{W}$ linkages.

Curve-fitting analysis of the $\mathrm{W} 4 \mathrm{f}$ peaks in $13.7 \mathrm{WZ}$ showed that they can be deconvoluted into three doublets ( $\mathrm{W}_{4} \mathrm{f}_{7 / 2}$ and $\mathrm{W} 4 \mathrm{f}_{5 / 2}$ ) with $\mathrm{W} 4 \mathrm{f}_{7 / 2}$ electron BEs of $34.6 \mathrm{eV}(76 \%), 35.4 \mathrm{eV}$ $(15 \%)$, and $35.8 \mathrm{eV}(9 \%)$. The bracketed values are the relative concentration of these species. The $\mathrm{BE}$ at $34.6 \mathrm{eV}$ is close to that reported for $\mathrm{W}^{5+}$. The higher BEs are close to the reported value of $\mathrm{W}^{6+}$ in similar catalyst system $(35.5 \mathrm{eV})$ [16]. Similarly, curve-fitting analysis of the corresponding $\mathrm{Zr} 3 \mathrm{~d}$ peaks in $13.7 \mathrm{WZ}$ showed that they can be deconvoluted into three doublets $\left(\mathrm{Zr} 3 \mathrm{~d}_{5 / 2}\right.$ and $\left.\mathrm{Zr} 3 \mathrm{~d}_{3 / 2}\right)$ with $\mathrm{Zr} 3 \mathrm{~d}_{5 / 2}$ electron BEs of $179.6 \mathrm{eV}(29 \%), 181.2 \mathrm{eV}(17 \%)$, and $182.4 \mathrm{eV}(54 \%)$. The last two are close to the corresponding $\mathrm{BE}$ of $\mathrm{Zr}^{4+}$ in bulk zirconia $(182.1 \mathrm{eV})$ [17]. The first one, however, appeared at a much lower BE than pure zirconia and indicates the presence of $\mathrm{Zr}^{3+}$ species. Indeed, $\mathrm{Zr}^{3+}$ species were observed in our $0.6 \mathrm{WZ}$ catalyst by EPR with $\mathrm{g} \perp=1.980$ [18].

From the integrated area of the XPS peaks and taking into consideration of the atomic sensitivity factor of $\mathrm{W}$ and $\mathrm{Zr}$, the surface $\mathrm{W} / \mathrm{Zr}$ ratio of each $\mathrm{WZ}$ sample can be calculated. The surface $W / Z r$ ratio increases roughly linearly as the loading of $\mathrm{W}$ in WZ increases (Fig. 4). 

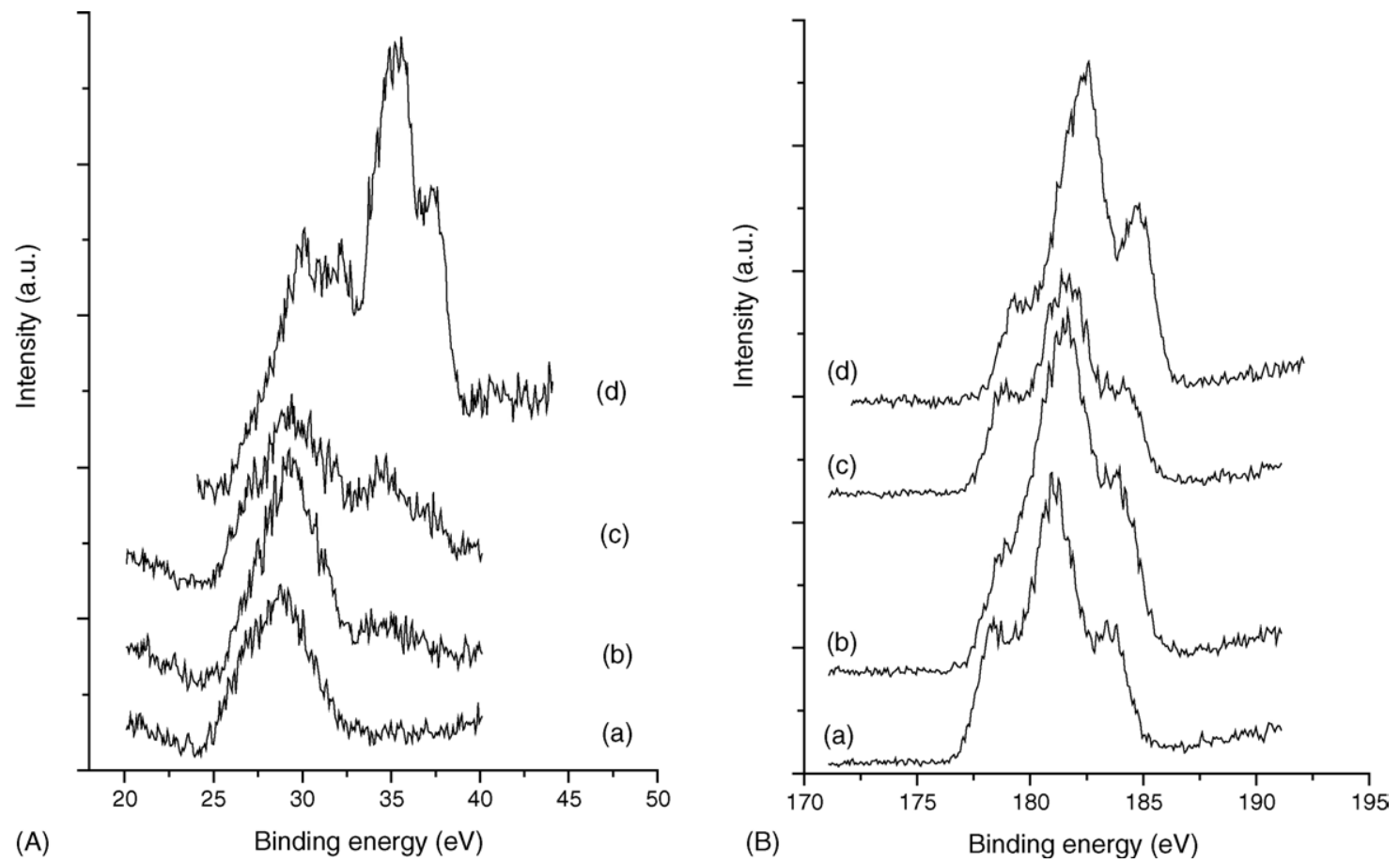

Fig. 3. (A) W 4f XPS spectra and (B) Zr 3d XPS spectra of (a) 0.6WZ; (b) 3.3WZ; (c) 10.1WZ; (d) $13.7 \mathrm{WZ}$.

\subsection{EXAFS study}

The Fourier-transformed $\mathrm{W}^{-} \mathrm{L}_{\mathrm{III}}$-edge EXAFS radial distribution function (RDF) of $0.6 \mathrm{WZ}$ (curve a), 13.7WZ (curve b), and $\mathrm{WO}_{3}$ (curve c) are compared in Fig. 5. These RDFs are not corrected for phase shifts. The three samples represent catalysts with tungstate species in three different states, that is, highly dispersed (a), monolayer (b), and bulk crystallites (c). Care should be taken in comparing intensity since their surface

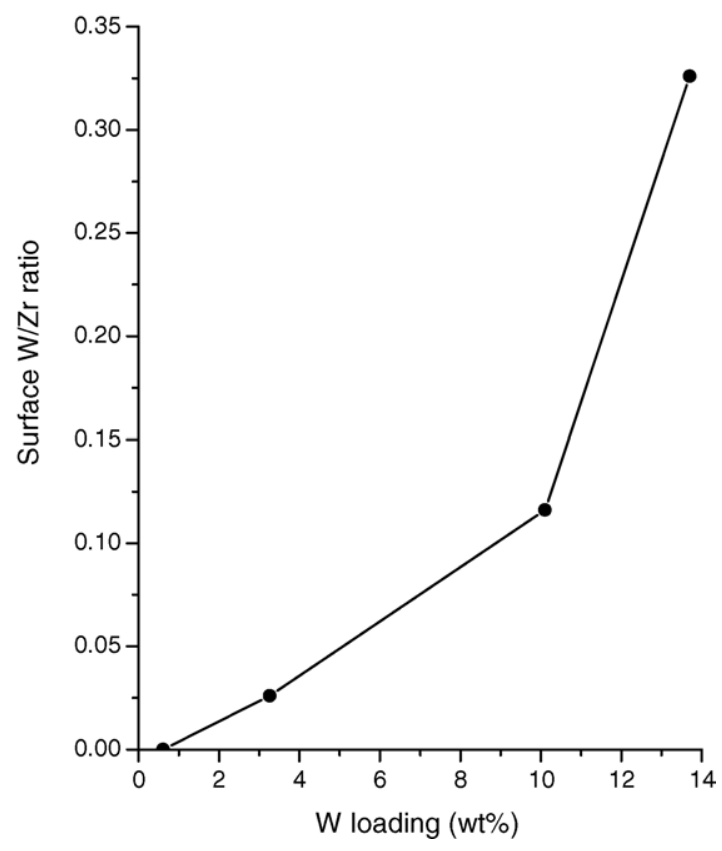

Fig. 4. Surface density of $\mathrm{WO}_{x}$ on WZ catalysts. tungstate species have different degree of structural disorderness. One should also note the low signal to noise ratio of $0.6 \mathrm{WZ}$ spectrum due to the very low $\mathrm{W}$ loading.

Subtle differences are observed among these catalysts. Firstly, we can see that bulk $\mathrm{WO}_{3}$ phase is not prominent in WZ

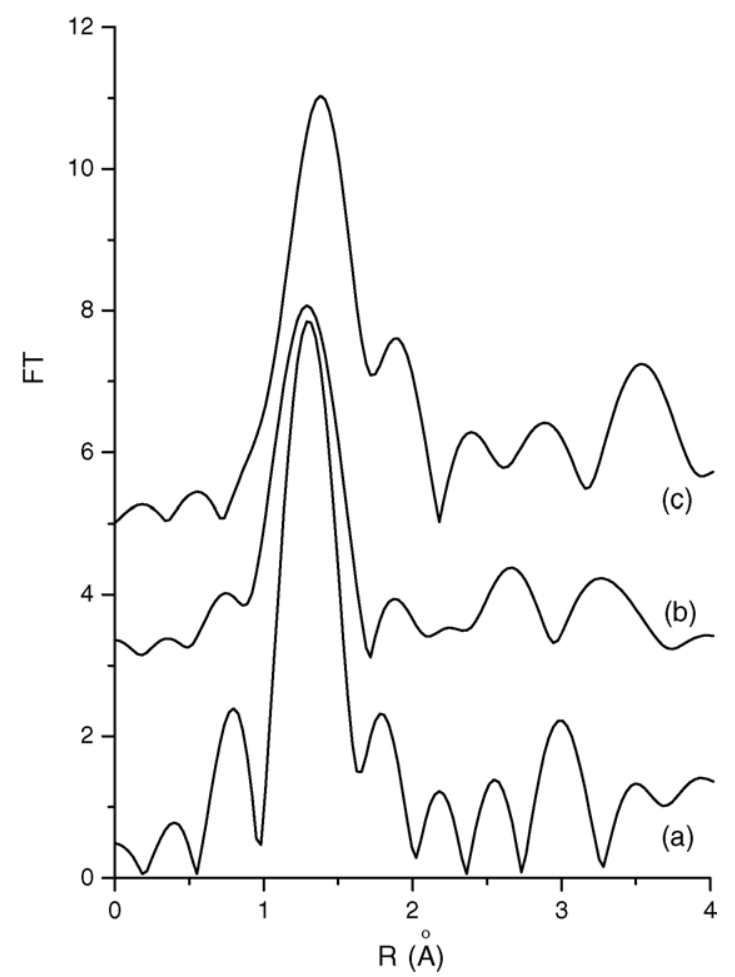

Fig. 5. Fourier-transformed W-L $\mathrm{LIII}^{-}$-edge EXAFS RDFs of (a) $0.6 \mathrm{WZ}$; (b) $13.7 \mathrm{WZ}$; (c) $\mathrm{WO}_{3}$. 


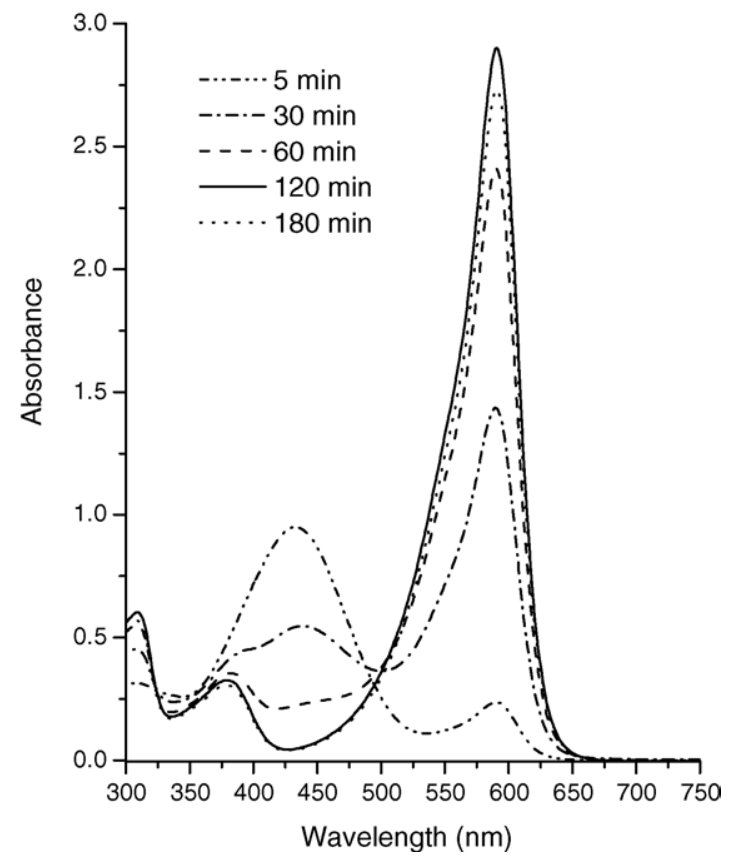

Fig. 6. UV-vis absorption spectra during the course of bromination reaction over $0.6 \mathrm{WZ}$ catalyst. Reaction conditions are: room temperature; $32 \mathrm{ml} 0.05 \mathrm{mM}$ phenol red solution; $0.1 \mathrm{M} \mathrm{NH}_{4} \mathrm{Br} ; 1.73 \times 10^{-3} \mathrm{mM} \mathrm{W} ; 11.3 \mathrm{mM} \mathrm{H}_{2} \mathrm{O}_{2}$.

samples judging from the peak intensity due to $\mathrm{W}-\mathrm{O}-\mathrm{W}$ distance at $3.53 \AA$ of curve $\mathrm{c}$. The shorter $\mathrm{W}-\mathrm{O}-\mathrm{W}$ linkages observed on WZ catalysts could be due to surface $\mathrm{WO}_{x}$ species interacting directly with zirconia surfaces [16]. One can see that the $\mathrm{W}-\mathrm{O}-\mathrm{W}$ linkage becomes shorter as $\mathrm{W}$ loading decreased. Secondly, the W-O peak intensity at about $1.29 \AA$ increased as the $\mathrm{W}$ loading decreased, reflecting less $\mathrm{W}=\mathrm{O}$ bonding. Lastly, the peak at $2.18 \AA$ also increased as W loading decreased, indicating the formation of more $\mathrm{W}-\mathrm{O}-\mathrm{Zr}$ linkages [16] when $\mathrm{W}$ is highly dispersed. In addition, some peaks at similar distance in $\mathrm{WO}_{3}$ have been assigned to multiple scattering [19].

Therefore, highly dispersed $0.6 \mathrm{WZ}$ catalyst showed four interesting features, that is, low $\mathrm{W}-\mathrm{O}-\mathrm{W}$ peak intensity, short $\mathrm{W}-\mathrm{O}-\mathrm{W}$ bond, plenty of $\mathrm{W}-\mathrm{O}$ and possibly $\mathrm{W}-\mathrm{O}-\mathrm{Zr}$ bonds .

\subsection{Catalytic study}

The conversion of phenol red into bromophenol blue can be followed readily by UV-vis absorption. For the $0.6 \mathrm{WZ}$ catalyst, the result is shown in Fig. 6. As the reaction proceeds, it can be easily seen that the peak at about $\lambda_{\max } \sim 590 \mathrm{~nm}$, corresponding to bromophenol blue, increases with time on stream up to $120 \mathrm{~min}$. At the same time, the peak corresponding to phenol red $\left(\lambda_{\max } \sim 432.5 \mathrm{~nm}\right)$ decreases as time on stream increases. Also, the peaks at 309 and $379 \mathrm{~nm}$ may be ascribed to the $\mathrm{O}_{2}{ }^{2-} \rightarrow \mathrm{W}$ charge transfer in the formation of peroxotungstates upon the addition of $\mathrm{H}_{2} \mathrm{O}_{2}[4,20]$. This is analogous to the peroxo form in $\mathrm{V}$ active site in vanadium bromoperoxidase [21].

In addition, both the bromination reactions in water and mixed solvent showed similar spectral feature. The kinetic
Table 1

Phenol red (PR) bromination over W-containing catalysts ${ }^{\mathrm{a}}$

\begin{tabular}{llllcc}
\hline Catalyst & $\begin{array}{l}\mathrm{PR} \\
(\mathrm{mM})\end{array}$ & $\begin{array}{l}\mathrm{H}_{2} \mathrm{O}_{2} \\
(\mathrm{mM})\end{array}$ & Solvent $^{\mathrm{b}}$ & $\begin{array}{l}\mathrm{TON}^{\mathrm{c}} \\
\left(\mathrm{h}^{-1}\right)\end{array}$ & $\begin{array}{l}\text { Surface area } \\
\left(\mathrm{m}^{2} \mathrm{~g}^{-1}\right)\end{array}$ \\
\hline $\mathrm{WO}_{4}{ }^{2-}-\mathrm{LDH}^{\mathrm{d}}$ & 0.05 & 10.0 & $\mathrm{Mix}$ & 109.6 & - \\
$0.6 \mathrm{WZ}$ & 0.05 & 13.2 & $\mathrm{Mix}$ & 37.4 & 44 \\
$0.6 \mathrm{WZ}$ & 0.05 & 11.3 & $\mathrm{H}_{2} \mathrm{O}$ & 31.3 & 44 \\
Filtrate & 0.05 & 11.3 & $\mathrm{H}_{2} \mathrm{O}$ & 0.09 & - \\
$3.3 \mathrm{WZ}$ & 0.05 & 11.5 & $\mathrm{H}_{2} \mathrm{O}$ & 24.2 & 54 \\
$13.7 \mathrm{WZ}$ & 0.05 & 11.1 & $\mathrm{H}_{2} \mathrm{O}$ & 0.85 & 78 \\
$0.7 \mathrm{~W} / \mathrm{m}-\mathrm{ZrO}_{2}$ & 0.05 & 15.2 & $\mathrm{H}_{2} \mathrm{O}$ & 71.6 & 105 \\
\hline
\end{tabular}

${ }^{a}$ Reaction is carried out at room temperature and with $0.1 \mathrm{M} \mathrm{NH}_{4} \mathrm{Br}$.

${ }^{b}$ For mixed solvent, the volume ratio of $\mathrm{H}_{2} \mathrm{O}: \mathrm{CH}_{3} \mathrm{OH}: \mathrm{C}_{4} \mathrm{H}_{8} \mathrm{O}=4: 3: 2$.

${ }^{c}$ TON is defined as the number of moles of $\mathrm{Br}^{-}$oxidized per mole of tungsten per hour.

${ }^{\mathrm{d}}$ Data taken from [4].

${ }^{\mathrm{e}}$ Residual activity of the filtered aqueous solution from 0.6WZ.

profiles of bromophenol blue formation versus reaction time over $0.6 \mathrm{WZ}$ catalyst showed that they increase almost linearly in the region up to $50 \%$ conversion of phenol red. In addition, the concentration of bromophenol blue passes a maximum and decreases a little at longer reaction time. The loss of bromophenol blue at this later stage is possibly due to further consecutive reactions.

Table 1 compares the performance of $\mathrm{WZ}$ and $\mathrm{W} / \mathrm{m}-\mathrm{ZrO}_{2}$ catalysts with literature reported $\mathrm{WO}_{4}{ }^{2-}-\mathrm{LDH}$ in phenol red bromination reaction. The surface area of these catalysts is also included. For the formation of one bromophenol blue molecule, four $\mathrm{Br}^{-}$are oxidized and incorporated into one phenol red molecule. The concentration of bromophenol blue was derived from the UV-vis absorbance by using an extinction coefficient (e) of $70.4 \mathrm{mM}^{-1} \mathrm{~cm}^{-1}$ at $\lambda_{\max }$ [4]. Turn-over number (TON) is defined as the number of moles of $\mathrm{Br}^{-}$oxidized per mole of tungsten per hour. We found that the bromination activity (TON) of WZ decreases with increasing $\mathrm{W}$ loading. The reaction activity of $0.6 \mathrm{WZ}$ in water and mixed solvent are comparable. By analyzing the change in the concentration of bromophenol blue in the filtered solution with time, the contribution from leached $\mathrm{WO}_{x}$ species to the overall activity was found to be negligible. Most importantly, $\mathrm{W} / \mathrm{m}-\mathrm{ZrO}_{2}$ has higher activity than WZ in this reaction.

Table 2

Phenol red (PR) bromination over $x \mathrm{~W} / \mathrm{m}-\mathrm{ZrO}_{2}$ catalysts $^{\mathrm{a}}$

\begin{tabular}{lllll}
\hline Catalyst & $\begin{array}{l}\text { TON } \\
\left(\mathrm{h}^{-1}\right)\end{array}$ & $\begin{array}{l}\text { Surface } \\
\text { area } \\
\left(\mathrm{m}^{2} \mathrm{~g}^{-1}\right)\end{array}$ & $\begin{array}{l}\text { Surface } \\
\text { density } \\
\left(\mathrm{W} / \mathrm{nm}^{2}\right)\end{array}$ & $\begin{array}{l}\text { Specific } \\
\text { activity } \\
\left(\mathrm{h}^{-1} \mathrm{~m}^{-2} \mathrm{~g}\right)\end{array}$ \\
\hline $0.3 \mathrm{~W} / \mathrm{m}-\mathrm{ZrO}_{2}$ & 57.0 & 121.0 & 0.08 & 0.47 \\
$0.6 \mathrm{~W} / \mathrm{m}-\mathrm{ZrO}_{2}$ & 62.0 & 120.7 & 0.16 & 0.51 \\
$0.7 \mathrm{~W} / \mathrm{m}-\mathrm{ZrO}_{2}$ & 62.3 & 117.8 & 0.19 & 0.53 \\
$1.1 \mathrm{~W} / \mathrm{m}-\mathrm{ZrO}_{2}$ & 70.0 & 118.5 & 0.30 & 0.59 \\
$1.3 \mathrm{~W} / \mathrm{m}-\mathrm{ZrO}_{2}$ & 83.8 & 119.2 & 0.36 & 0.70 \\
$1.4 \mathrm{~W} / \mathrm{m}-\mathrm{ZrO}_{2}$ & 63.7 & 120.0 & 0.38 & 0.53 \\
$1.5 \mathrm{~W} / \mathrm{m}-\mathrm{ZrO}_{2}$ & 60.9 & 125.4 & 0.39 & 0.49 \\
$1.6 \mathrm{~W} / \mathrm{m}-\mathrm{ZrO}_{2}$ & 41.7 & 122.3 & 0.43 & 0.34
\end{tabular}

${ }^{\mathrm{a}}$ Reaction conditions: room temperature, $0.05 \mathrm{mM} \mathrm{PR}, 27.7 \mathrm{mM} \mathrm{H}_{2} \mathrm{O}_{2}$, $0.1 \mathrm{M} \mathrm{NH}_{4} \mathrm{Br}$, and $\mathrm{H}_{2} \mathrm{O}$ was used as the solvent. 


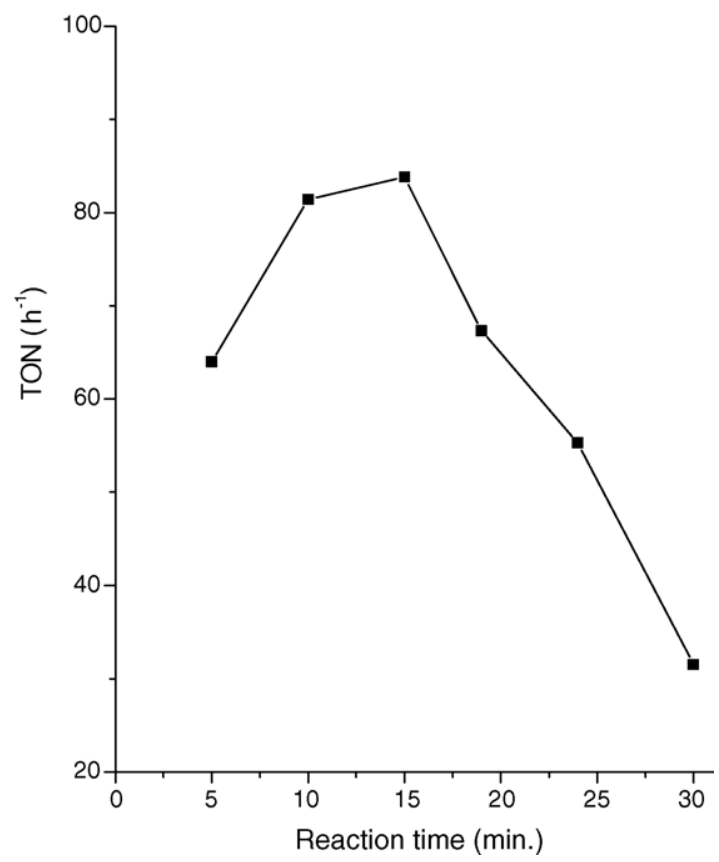

Fig. 7. Kinetic profile of phenol red bromination versus reaction time over $1.3 \mathrm{~W} / \mathrm{m}-\mathrm{ZrO}_{2}$ catalyst. Reaction conditions are the same as Table 2.

Table 2 compares the activity of $x \mathrm{~W} / \mathrm{m}-\mathrm{ZrO}_{2}$ catalysts. The percentage of $\mathrm{W}$ is calculated according to the amount of tungsten precursor added during catalyst preparation. However, they are not far from the values determined experimentally. Here, the activity of phenol red bromination does not vary inversely with $\mathrm{W}$ loading as in the case of WZ. A maximum is observed at $1.3 \mathrm{wt} \%$ of $\mathrm{W}$. On the other hand, the surface area of all the catalysts is comparable in magnitude. Surprisingly, a higher concentration of $\mathrm{H}_{2} \mathrm{O}_{2}$ used did not result in higher activity (compared $0.7 \mathrm{~W} / \mathrm{m}-\mathrm{ZrO}_{2}$ catalysts in Tables 1 and 2).

Fig. 7 shows the variation of catalytic activity with time on stream over $1.3 \mathrm{~W} / \mathrm{m}-\mathrm{ZrO}_{2}$ catalyst. Its bromination activity decays quickly after $15 \mathrm{~min}$ of reaction. On the other hand, the initial activity of $0.6 \mathrm{WZ}$ can be maintained even after $1 \mathrm{~h}$ of reaction.

\section{Discussion}

We have shown that decreasing the loading of $\mathrm{W}$ is an easy way of decreasing its surface density on WZ as indicated by the surface W/Zr ratio. Similar finding is also reported by Baertsch et al. [22]. However, characterizing the structure of $\mathrm{W}$ active site in a low surface density catalyst, such as $0.6 \mathrm{WZ}$, is always faced with the problem of limiting signal intensity. To deduce its structure, higher $\mathrm{W}$ loaded catalysts are also studied.

The W-O-W coordination number should decrease with W loading. However, it may not be advisable to obtain this information directly by comparing the intensity of the EXAFS spectra since tungstate ion in different structural phase has different degree of structural disorderness. One thing we are sure is that $\mathrm{W}-\mathrm{O}-\mathrm{W}$ coordination number in $0.6 \mathrm{WZ}$ is low indicating a low degree of oligomerization. Also, the short $\mathrm{W}-$ $\mathrm{O}-\mathrm{W}$ in $0.6 \mathrm{WZ}$ tells us that the tungstate ions are all dispersed on the zirconia surface. As the degree of $\mathrm{W}$ dispersion increases, this kind of interfacial interaction tends to decrease the number of $\mathrm{W}=\mathrm{O}$ group with the concurrent increase in the number of $\mathrm{W}-\mathrm{O}$ and $\mathrm{W}-\mathrm{O}-\mathrm{Zr}$ groups. Therefore, the observed large increase in the number of $\mathrm{W}-\mathrm{O}$ and $\mathrm{W}-\mathrm{O}-\mathrm{Zr}$ groups in $0.6 \mathrm{WZ}$ is in line with the high degree of $\mathrm{W}$ dispersion observed by XRD and XPS. We suggest that $\mathrm{WO}_{x}$ on $0.6 \mathrm{WZ}$ presumably exists as monomer and dimer. A case for monomer is indicated in Eq. (3).

In the work of Sels et al. [4], it is not surprising that $\mathrm{WO}_{4}{ }^{2-}$-LDH has very high activity in phenol red bromination reaction since the $\mathrm{WO}_{4}{ }^{2-}$ ions are atomically dispersed on $\mathrm{LDH}$. In addition, the $\mathrm{WO}_{4}{ }^{2-}$ ion contains more oxo groups which withdraw electron strongly to activate the peroxo group [19]. The bromination activity of WZ decreases as the loading of $\mathrm{W}$ increases due to the decreased dispersion of $\mathrm{WO}_{x}$ on zirconia. In addition, the very low surface density of $\mathrm{WO}_{x}$ in $0.6 \mathrm{WZ}$ provides enough zirconia surfaces for the adsorption of bulky phenol red molecules while not blocking the $\mathrm{WO}_{x}$ active sites. Furthermore, the bromination activity of $0.6 \mathrm{WZ}$ (surface area $=44 \mathrm{~m}^{2} \mathrm{~g}^{-1}$ ) is lower than $0.7 \mathrm{~W} / \mathrm{m}$ $\mathrm{ZrO}_{2}$ (surface area $=109 \mathrm{~m}^{2} \mathrm{~g}^{-1}$ and pore size $=36 \AA$ ). The activity of the latter catalyst is at least $50 \%$ of the best catalyst $\left(\mathrm{WO}_{4}{ }^{2-}-\mathrm{LDH}\right)$ reported in the literature. Therefore, higher degree of dispersion of $\mathrm{WO}_{x}$ on the support seems to improve on its catalytic activity. Recently, Figueras et al. [23] studied the oxidation of dibenzothiophene by $\mathrm{H}_{2} \mathrm{O}_{2}$ over zirconia supported $\mathrm{W}$ catalysts and found that catalysts containing highly dispersed $\mathrm{W}$ cations are more active than $\mathrm{WO}_{3}$ clusters.

In Table 2 , one can see that $x \mathrm{~W} / \mathrm{m}-\mathrm{ZrO}_{2}$ showed an optimum activity at $1.3 \mathrm{wt} \%$ of $\mathrm{W}$ but the reason for this is still not known. But, we note that $1.3 \mathrm{~W} / \mathrm{m}-\mathrm{ZrO}_{2}$ has roughly the same degree of dispersion as $0.6 \mathrm{WZ}$ due to the higher surface area in $\mathrm{m}-\mathrm{ZrO}_{2}$. However, its activity also decays quickly and reaches a value comparable to that of $\mathrm{WZ}$. The catalyst deactivation observed in $x \mathrm{~W} / \mathrm{m}-\mathrm{ZrO}_{2}$ may be due to blocking of channels either by the strongly adsorbing bromophenol blue or other products formed via consecutive reactions, thus, limits further diffusion of reactant to the internal active sites.

The adsorption sites on zirconia for phenol red are probably the coordinatively unsaturated $\mathrm{Zr}^{3+}$ which have been suggested as the center of adsorption for $\mathrm{CO}_{2}[24,25]$. We have also found that $0.6 \mathrm{WZ}$ has the capability to adsorb $\mathrm{CO}_{2}$ and the phenol red molecule probably interacts with $\mathrm{Zr}^{3+}$ site through the $\mathrm{SO}_{2}$ group. We have done surface titration study on $0.6 \mathrm{WZ}$ with phenol red in aqueous medium and found that the sample colour changed quickly from white to pink whereas no such change is observed on $0.5 \mathrm{~W} / \mathrm{SiO}_{2}$. This result shows that some kind of basic sites (besides $\mathrm{Zr}^{3+}$ ) are also present on zirconia and adsorb the phenol red molecules.

Regarding the active sites for the redox reaction, the nature of $\mathrm{WO}_{x}$ sites (whether monomer or dimer) in $0.6 \mathrm{WZ}$ may not have significant steric effect on the catalytic activity since the $\mathrm{Br}^{-}$and $\mathrm{H}_{2} \mathrm{O}_{2}$ involved in the formation of the brominating agent on these sites are small molecules. Even in $3.3 \mathrm{WZ}$, such monomeric or dimeric redox sites may still be the dominant 
species on the surface. This probably explains why the activity of $3.3 \mathrm{WZ}$ (surface area $=54 \mathrm{~m}^{2} \mathrm{~g}^{-1}$ ) is not much less than that of $0.6 \mathrm{WZ}$. It also has enough zirconia surfaces for the adsorption of bulky phenol red molecules. In 13.7WZ (surface area $=78 \mathrm{~m}^{2} \mathrm{~g}^{-1}$ ), the situation is totally different as the loading of $\mathrm{W}$ on zirconia is higher than monolayer coverage and large crystallites are formed on the surface (see Fig. 1). Therefore, much lower activity is observed for this sample.

It is known that one possible active site for interacting with $\mathrm{H}_{2} \mathrm{O}_{2}$ is the isolated $\mathrm{W}=\mathrm{O}$ group $[19,26]$, the $\mathrm{OH}$ leaving group can be generated in-situ during the addition reaction as follows:

$$
\begin{aligned}
& \mathrm{W}=\mathrm{O}+\mathrm{H}_{2} \mathrm{O}_{2} \rightarrow \mathrm{HO}-\mathrm{W}-\mathrm{OOH} \\
& \mathrm{HO}-\mathrm{W}-\mathrm{OOH} \rightarrow \mathrm{W}\left(\mathrm{O}_{2}\right)+\mathrm{H}_{2} \mathrm{O} \\
& \mathrm{W}\left(\mathrm{O}_{2}\right)+\mathrm{Br}^{-} \rightarrow \mathrm{W}=\mathrm{O}+\mathrm{OBr}^{-}
\end{aligned}
$$

$\mathrm{W}\left(\mathrm{O}_{2}\right)$ is the peroxo species.

When an -OH group is also present, it can be substituted by a hydroperoxo group facilely under an acidic condition as shown in Eq. (3). The hydroperoxo species then transforms to the peroxo species as in Eq. (4) with the regeneration of an $-\mathrm{OH}$ group.

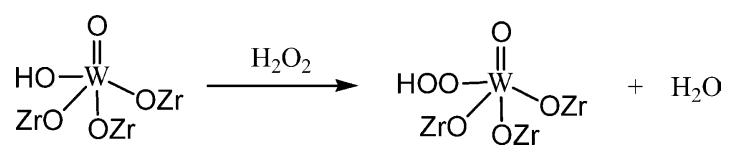

$\mathrm{O}=\mathrm{W}-\mathrm{OOH} \rightarrow \mathrm{HO}-\mathrm{W}\left(\mathrm{O}_{2}\right)$

$\mathrm{HO}-\mathrm{W}\left(\mathrm{O}_{2}\right)$ can then be further attacked by bromide and the original active site is regenerated. Unfortunately, W-OH IR signal overlaps with that of $\mathrm{Zr}-\mathrm{OH}$ in our sample and made its study difficult. We have not yet studied in details how the rate of reaction occurring on oxo and hydroxyl-oxo sites differs and much work is needed in this area.

The activity of our catalysts is nearly $50 \%$ of $\mathrm{WO}_{4}{ }^{2-}-\mathrm{LDH}$ and seems to suggest that at most one oxo group per $\mathrm{W}$ center is involved in bromination reaction as in Eq. (3). Surface characterization study of WZ by Scheithauer et al. [27] with Raman and FTIR spectroscopies also showed no evidence on the existence of di-oxo species. It is also tempting to suggest isolated $\mathrm{W}-\mathrm{OH}$ as one of the precursor site for this reaction. $\mathrm{W}-$ $\mathrm{OOH}$ can be formed by direct substitution reaction with $\mathrm{H}_{2} \mathrm{O}_{2}$. However, we do not know whether the hydroperoxo group can interact directly with bromide ion without prior transformation to the peroxo species.

The bromination activity of WZ seems not much affected by the solvent used in the reaction, and high catalytic activity can be obtained even in water. This finding is unlike the general trend reported in the literature that bromination activity of a catalyst is usually lower in water than organic solvent due to the instability of the peroxo-tungstate species in water $[19,26]$. As shown in the UV-vis absorption spectrum in Fig. 6, the peroxo- tungstate species on WZ are apparently stable in aqueous medium. Therefore, tungstated zirconia should be a good choice of catalyst when the reaction has to be done in water or acidic medium. As the surface of these catalysts is nonionic, it is likely that the coordination environment of the peroxotungstate species on these surfaces is different from that of ionic surfaces.

In conclusion, we have demonstrated that tungstated zirconia at high dispersion are very active bromination catalysts and can be used as biomimetic catalysts for vanadium bromoperoxidase. This will open up a new direction for the application of these well-known catalysts and there are plenty room for improvements. Although the formation of $\mathrm{W}-\mathrm{O}-\mathrm{Zr}$ linkages limits the number of $\mathrm{W}=\mathrm{O}$ groups participated in the bromination reaction to one, it has the advantage of anchoring the $\mathrm{WO}_{x}$ active sites firmly on zirconia surfaces to give a highly dispersed and stable catalyst. This catalyst may be further exploited for the related bromide-assisted oxidation reactions with $\mathrm{H}_{2} \mathrm{O}_{2}$ [28].

$\mathrm{W} / \mathrm{m}-\mathrm{ZrO}_{2}$ catalyst has many promising features such as: (i) high catalytic activity, (ii) pore structure for shape selectivity, (iii) thermal stability (at least $630{ }^{\circ} \mathrm{C}$ ) for catalyst regeneration, and (iv) stable to acid and base. One only has to improve the stability in activity. It will be investigated in great details in the future.

\section{Acknowledgement}

This work was supported by a grant from the National Science Council of Taiwan through Academy Excellence program (NSC-93-2752-M-002-PAE).

\section{References}

[1] A. Butler, J.V. Walker, Chem. Rev. 93 (1993) 1937.

[2] R.M. Tótaro, P.A.M. Williams, M.C. Apella, M.A. Blesa, E.J. Baran, J. Chem. Soc. Dalton Trans. (2000) 4403.

[3] B.F. Sels, D. De Vos, M. Buntinx, F. Pierard, A. Kirsch-De Mesmaeker, P. Jacobs, Nature 400 (1999) 855.

[4] B.F. Sels, D.E. De Vos, M. Buntinx, P.A. Jacobs, J. Catal. 216 (2003) 288.

[5] B.F. Sels, D.E. De Vos, P.A. Jacobs, Angew. Chem. Int. Ed. 44 (2005) 310.

[6] B. Sels, P. Levecque, R. Brosius, D. De Vos, P. Jacobs, D.W. Gammon, H.H. Kinfe, Adv. Synth. Catal. 347 (2005) 93

[7] Z.P. Xu, G.Q. Lu, Chem. Mater. 17 (2005) 1055.

[8] M.S. Morey, J.D. Bryan, S. Schwarz, G.D. Stucky, Chem. Mater. 12 (2000) 3435 .

[9] D.G. Barton, S.L. Soled, G.D. Meitzner, G.A. Fuentes, E. Iglesia, J. Catal. 181 (1999) 57.

[10] S.T. Wong, T. Li, S. Cheng, J.F. Lee, C.Y. Mou, J. Catal. 215 (2003) 45.

[11] U. Ciesla, M. Fröba, G. Stucky, F. Schüth, Chem. Mater. 11 (1999) 227.

[12] J.H. Wang, C.Y. Mou, Appl. Catal. A 286 (2005) 128.

[13] V.V. Srdic, M. Winterer, Chem. Mater. 15 (2003) 2668

[14] W. Hertl, Langmuir 5 (1989) 96.

[15] B. Bachiller-Baeza, I. Rodriguez-Ramos, A. Guerrero-Ruiz, Langmuir 14 (1998) 3556.

[16] M. Valigi, D. Gazzoli, I. Pettiti, G. Mattei, S. Colonna, S. De Rossi, G. Ferraris, Appl. Catal. A 231 (2002) 159.

[17] S. Ardizzone, C.L. Bianchi, Surf. Interface Anal. 30 (2000) 77.

[18] J. Matta, J.F. Lamonier, E. Abi-Aad, E.A. Zhilinskaya, A. Aboukaïs, Phys. Chem. Chem. Phys. 1 (1999) 4975.

[19] T. Pauporte, Y. Soldo-Olivier, R. Faure, J. Phys. Chem. B 107 (2003) 8861. 
[20] M.H. Dickman, M.T. Pope, Chem. Rev. 94 (1994) 569.

[21] D.C. Crans, J.J. Smee, E. Gaidamauskas, L.Q. Yang, Chem. Rev. 104 (2004) 849.

[22] C.D. Baertsch, S.L. Soled, E. Iglesia, J. Phys. Chem. B 105 (2001) 1320.

[23] F. Figueras, J. Palomeque, S. Loridant, C. Fèche, N. Essayem, G. Gelbard, J. Catal. 226 (2004) 25.

[24] Y. Kohno, T. Tanaka, T. Funabiki, S. Yoshida, J. Chem. Soc. Faraday Trans. 94 (1998) 1875
[25] C. Morterra, E. Giamello, L. Orio, M. Volante, J. Phys. Chem. B 94 (1990) 3111.

[26] G.J. Colpas, B.J. Hamstra, J.W. Kampf, V.L. Pecoraro, J. Am. Chem. Soc. 118 (1996) 3469.

[27] M. Scheithauer, R.K. Grasselli, H. Knözinger, Langmuir 14 (1998) 3019.

[28] B.F. Sels, D.E. De Vos, M. Buntinx, P.A. Jacobs, J. Am. Chem. Soc. 123 (2001) 8350. 